\title{
Converged Networking: A Review of Concepts and Technologies
}

\author{
Adel Ahmed Ali and Ahmed M. Al-Naamany
}

Department of Electrical, Electronics and Computer Engineering, College of Engineering, Sultan Qaboos University, P.O. Box 33, Al Khod 123, Muscat, Sultanate of Oman.

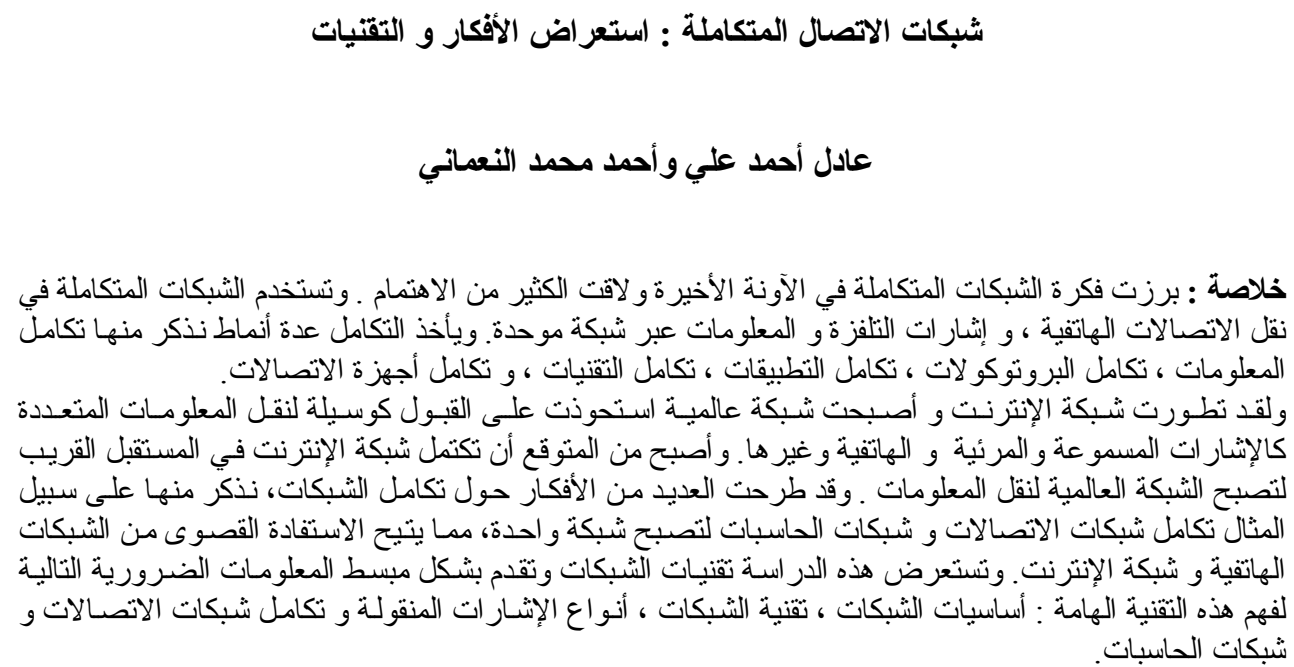

ABSTRACT: Converged networking is an emerging technology thrust that integrates voice, video, and data traffic on a single network. Converged networking encompasses several aspects, all of which are related to the aggregation of networking activity. Such aspects include, Payload convergence, Protocol convergence, Physical convergence, Device convergence, Application convergence, Technology convergence, etc. In recent years the Internet has developed into a global data network that is highly accepted as a multimedia information platform, which has the potential to develop into an alternative carrier network in the future. Several convergence scenarios have been recently proposed, ranging from integrating communication services and computer application into two separate networks, to building a seamless multimedia network, which converges the Central Office based network and the Internet in a single network, thereby enabling telecommunications operators and service provider's tremendous investment in existing network infrastructure to be fully utilized. This paper offers introduction and review of the networking technologies. The paper presents the existing multiple networks into two infrastructures: an ATM/Frame Relay (Ethernet)based corporate network with integrated voice, video, and data traffic and an Internet-based network for secure intranet, extranet and remote access. This work is aimed at summarizing the internetworking basics and technologies which are essential for the emerging converged networking systems. The specific areas addressed here are networking basics, networking technologies, types of traffic, and convergence of computer and communication networks. 


\section{CONTENTS}

Introduction $\quad 211$

Internetworking Basics $\quad 212$

2.1 Open Systems Interconnection (OST) References Model 214

2.2 Transmission Control Protocol/Internet Protocol (TCP/IP) 216

2.3 Information Formats 216

2.4 Connection-Oriented and Connectionless Network Services 217

3. Networking Technologies 217

$\begin{array}{ll}3.1 \text { Asynchronous Transfer Mode (ATM) } & 217\end{array}$

$\begin{array}{ll}3.2 \text { Ethernet } & 218\end{array}$

3.3 Frame Relay 218

3.4 Synchronous Optical Network (SONET) and Board-band Integrated Service Digital
Network (BISDN)

3.5 Fiber Distributed Data Interface (FDDI) 219

3.6 Digital Subscriber Line $\quad 219$

3.7 Asymmetric Digital Subscriber Line (ADSL) 220

4. Multimedia 220

4.1 Multimedia Technologies and Standards 220

4.2 Compression Standards 220

5. Converged Networking 220

5.1 Convergence Between Public Switching and the Internet 220

5.2 Convergence Between ATM and Ethernet 221

6. Concluding Remarks 224

7. References 225

Nomenclature

$\begin{array}{ll}\text { ATM } & \text { Asynchronous Transfer Mode } \\ \text { BGP } & \text { Border Gateway Protocol } \\ \text { BISDN } & \text { Broadband Integrated Services Digital Network } \\ \text { CATV } & \text { Cable Television } \\ \text { CMIP } & \text { Common Management Information Protocol } \\ \text { CSMA/CD } & \text { Carrier-sense multiple access with collision detection } \\ \text { FTAM } & \text { File Transfer Access and Management } \\ \text { FTP } & \text { File Transfer Protocol } \\ \text { GIF } & \text { Graphics Interchange Format } \\ \text { IEEE } & \text { The Institute of Electrical and Electronic Engineers } \\ \text { IP } & \text { Internet Protocol } \\ \text { ISO } & \text { International Organization for Standardization } \\ \text { ISP } & \text { Internet Service Provider } \\ \text { LAN } & \text { Local area network } \\ \text { LLC } & \text { Logical Link Control } \\ \text { MAC } & \text { Media Access Control } \\ \text { MMF } & \text { Multimode Fiber } \\ \text { MPEG } & \text { Motion Picture Experts Group } \\ \text { NIC } & \text { Network Interface Card } \\ \text { NBP } & \text { Name Binding Protocol } \\ \text { NSP } & \text { Network Service Provider } \\ \text { OSI } & \text { Open Systems Interconnection } \\ \text { OSPF } & \text { Open Shortest Path First }\end{array}$




\section{CONVERGED NETWORKING}

$\begin{array}{ll}\text { QoS } & \text { Quality of Service } \\ \text { PACE } & \text { Priority access control } \\ \text { PPP } & \text { Point to Point Protocol } \\ \text { POTS } & \text { Plain Old Telephony System } \\ \text { RIP } & \text { Routing Information Protocol } \\ \text { SCP } & \text { Session Control Protocol } \\ \text { SDMS } & \text { Switched Multi-megabit Data Service } \\ \text { SMF } & \text { Single-mode fiber } \\ \text { SMTP } & \text { Simple Mail Transfer Protocol } \\ \text { SNA } & \text { System Network Architecture } \\ \text { SDH } & \text { Synchronous Digital Hierarchy } \\ \text { SONET } & \text { Synchronous Optical Network } \\ \text { TCP } & \text { Transmission Control Protocol } \\ \text { TCP/IP } & \text { Transmission Control Protocol/Internet Protocol } \\ \text { TIFF } & \text { Tagged Image File Format } \\ \text { VTP } & \text { Virtual Terminal Protocol } \\ \text { WAN } & \text { Wide-Area Network } \\ \text { ZIP } & \text { Zone Information Protocol }\end{array}$

\section{Introduction}

R ecently the world has seen the introduction of converged information Technology applications. We are now seeing computers mimicking the telephone and televisions as well as elementary teleconferencing. The advent of television, which will incorporate some of computer functions and telephone, is now also a reality. However apart from all of the above the major advancement is on the industrial networks and work place, which converged networking, applications are on the rise. This review paper aims to cover the Internetworking basics and technologies as well as the types of traffics (CISCO 1997).

Converged Networking is an emerging technology thrust that integrates voice, video, and data traffic on a single network. The market drivers for converged networks are cost reduction; support for sophisticated, highly integrated applications; and the provision of greater network flexibility and functionality (Collins et.al. 1997) and (Rafter 1997). Payload convergence is that aspect of converged networking wherein different data types are carried in the same communications format. Protocol convergence is the movement away from multi-protocol to single protocol (typically IP) networks (Cisco 1997). Physical convergence occurs when payloads travel over the same physical network equipment regardless of their service requirements. Device convergence describes the trend in network device architecture to support different networking paradigms in a single system. Application convergence represents the appearance of applications that integrate formerly separate functions. Technology convergence signifies the move toward common networking technologies that satisfy both LAN and WAN requirements.

New technologies spur new application development, and new applications, in turn, fuel the need for further technology advancements. In a relatively short time span, network connections have evolved from shared or switched Ethernet to shared or switched Fast Ethernet to accommodate rising bandwidth demand. Within the enterprise networks, business applications are now advancing to embrace highresolution graphics, video, and other rich media types that exceed the capacity of even Fast Ethernet performance. This latest generation of bandwidth-intensive applications can be organized into four categories as depicted in figure 1, i.e. scientific modeling, medical imaging applications, multimedia and graphical publication and finally video and videoconference applications that are getting bigger in size from megabytes to gigabytes to terabytes. 
Internet and intranet applications create unpredictable any-to-any traffic patterns. Increasingly, with servers distributed across the enterprise and users accessing Web sites inside and outside the corporate network, there is no way to predict where traffic will go. Data warehousing and backup applications handle gigabytes or terabytes of data distributed among hundreds of servers and storage systems.

Bandwidth-intensive group-ware applications such as desktop videoconferencing, interactive whiteboarding, and real-time video that support mission-critical business applications not only require more raw bandwidth, they also demand low latency and limited jitter to be effective to accommodate bandwidthintensive applications, two networking technologies are available, with products and technical support, viz., ATM, Frame Relay and Gigabit Ethernet. For the last few years, there has been considerable debate over whether ATM or Gigabit Ethernet will win in the marketplace (Chang et.al 1999 and Braden et.al. 1994). On the other hand, the Internet has developed to become a global data network, which attracts numerous users, especially with the variety of information and multimedia applications offered online. Although still in its infancy with regard to reliability and guaranteed grade of service, the Internet is highly accepted as an information platform by users and information content providers alike. The high investments being made in the Internet by the computer industry, network carriers, and service providers may prove that the Internet will meet the expectations for exponential growth predicted by analysts and boosted performance claimed by the Internet industry (White et.al. 1997).

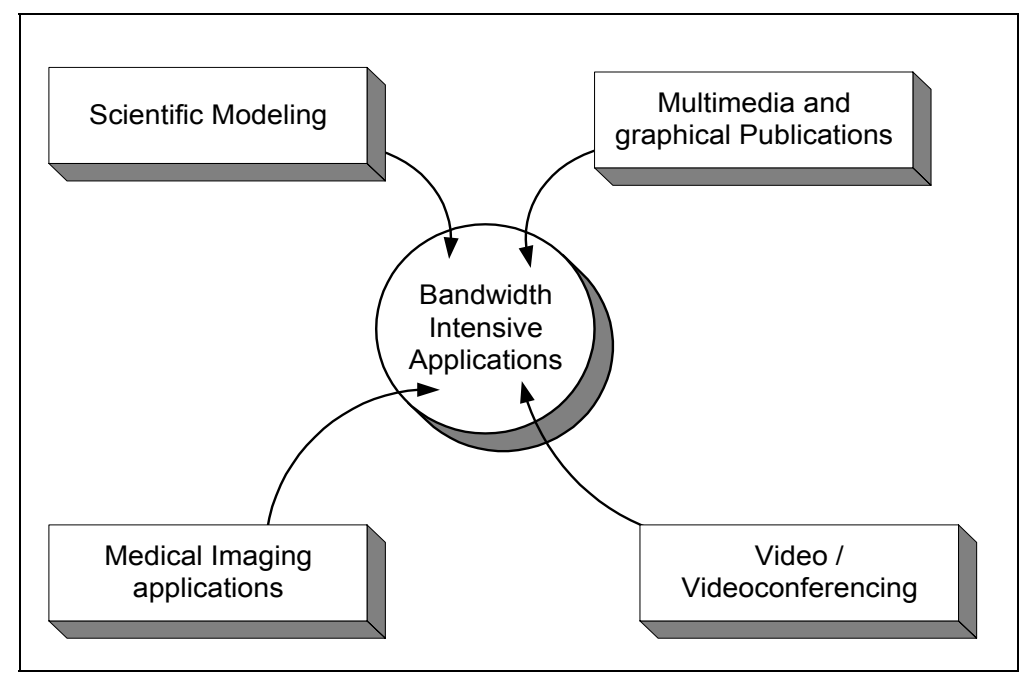

Figure 1. Categories of bandwidth intensive applications

This paper is organized as follows: in Section 2 internetworking basics are summarized. Networking technologies are presented in Section 3, followed by a summary of the main features of the multimedia traffic in Section 4. A converged networking based on (ATM- Frame Relay-Ethernet)/ (Internet) is presented in Section 5, and some concluding remarks are summarized in Section 6.

\section{Internetworking Basics}

Different media (audio, video, animation, data) are included in multimedia-networked applications, thus leading to the integrated services information infrastructure concept. The infrastructure is composed of terminals and servers interconnected by means of data links (pipes) via intermediate network nodes. 


\section{CONVERGED NETWORKING}

Network nodes are routing and switching devices to implement the required exchange of information among network hosts. Networks are usually equipped with data links (either physical links or links realized by sub networks), by switches and routers, and by auxiliary network servers. Network servers typically provide real-time address translation and routing functions; or they serve for network and service management tasks, including service billing.

Table 1. Summary of WAN technologies

\begin{tabular}{|l|l|}
\hline \multicolumn{1}{|c|}{ WAN Technology } & \multicolumn{1}{c|}{ Typical Uses } \\
\hline $\begin{array}{l}\text { Asymmetric Digital Subscriber } \\
\text { Line (ADSL) }\end{array}$ & $\begin{array}{l}\text { A new modem technology. Coverts existing twisted pair telephone } \\
\text { lines into access path for multimedia ad high-speed data } \\
\text { communications. ADSL transmits more than 6 Mbps to a subscriber } \\
\text { and as much as 640 kbps more in both directions. }\end{array}$ \\
\hline Analog modem & $\begin{array}{l}\text { Used by telecommuters and mobile users who access the network less } \\
\text { than two hours per day or for backup for another type of link. }\end{array}$ \\
\hline Leased line & $\begin{array}{l}\text { Leased lines can be used for Point to point Protocol (PPP) networks } \\
\text { and hub and spoke topologies, or for backup for another type of link. }\end{array}$ \\
\hline $\begin{array}{l}\text { Integrated Services } \text { Digital } \\
\text { Networks (ISDN) }\end{array}$ & $\begin{array}{l}\text { ISDN can be used for cost effective remote access to corporate } \\
\text { networks. It can be used in both private and carrier provided } \\
\text { networks. }\end{array}$ \\
\hline Frame Relay & $\begin{array}{l}\text { Frame Relay provides a cost effective, high speed, low latency mesh } \\
\text { topology between remote sites. It can be used in both private and } \\
\text { carrier provided networks. }\end{array}$ \\
\hline $\begin{array}{l}\text { Switched Multi megabit Data } \\
\text { Service (SMDS) }\end{array}$ & $\begin{array}{l}\text { SMDS provides high speed, high performance connections across } \\
\text { public data networks. It can also be deployed in metropolitan area } \\
\text { networks (MANs). }\end{array}$ \\
\hline X.25 & $\begin{array}{l}\text { X.25 can provide a reliable WAN circuit or backbone. It also provides } \\
\text { support for legacy applications. }\end{array}$ \\
\hline WAN, ATM & $\begin{array}{l}\text { WAN and ATM can be used to accelerate bandwidth requirements. It } \\
\text { also provides support for multiple QoS classes for differing } \\
\text { application requirements for delay and loss. }\end{array}$ \\
\hline
\end{tabular}

An inter-network is a collection of individual networks, connected by intermediate networking devices that functions as a single large network. Internetworking refers to the industry, products, and procedures that meet the challenge of creating and administering inter-networks. LANs evolved around the PC revolution. LANs enabled multiple users in a relatively small geographical area to exchange files and messages, as well as access shared resources such as file servers. WANs interconnect LANs across normal telephone lines (and other media), thereby interconnecting geographically dispersed users. Table 1 presents a summary of WAN technologies.

Today, high-speed LANs and switched inter-networks are becoming widely used, largely because they operate at very high speeds and support such high-bandwidth applications as voice and videoconferencing. Internetworking evolved as a solution to three key problems: isolated LANs, duplication of resources, and a lack of network management. Isolated LANS made electronic communication between different offices or departments impossible. Duplication of resources meant that the same hardware and software had to be supplied to each office or department, as did a separate support staff. This lack of network management meant that no centralized method of managing and troubleshooting networks existed. 


\subsection{Open Systems Interconnection (OSI) Reference Model}

The OSI reference model describes how information from a software application in one computer moves through a network medium to a software application in another computer. OSI is a conceptual model composed of seven layers, each specifying particular network functions as shown in figure 2 (Comer 1999).

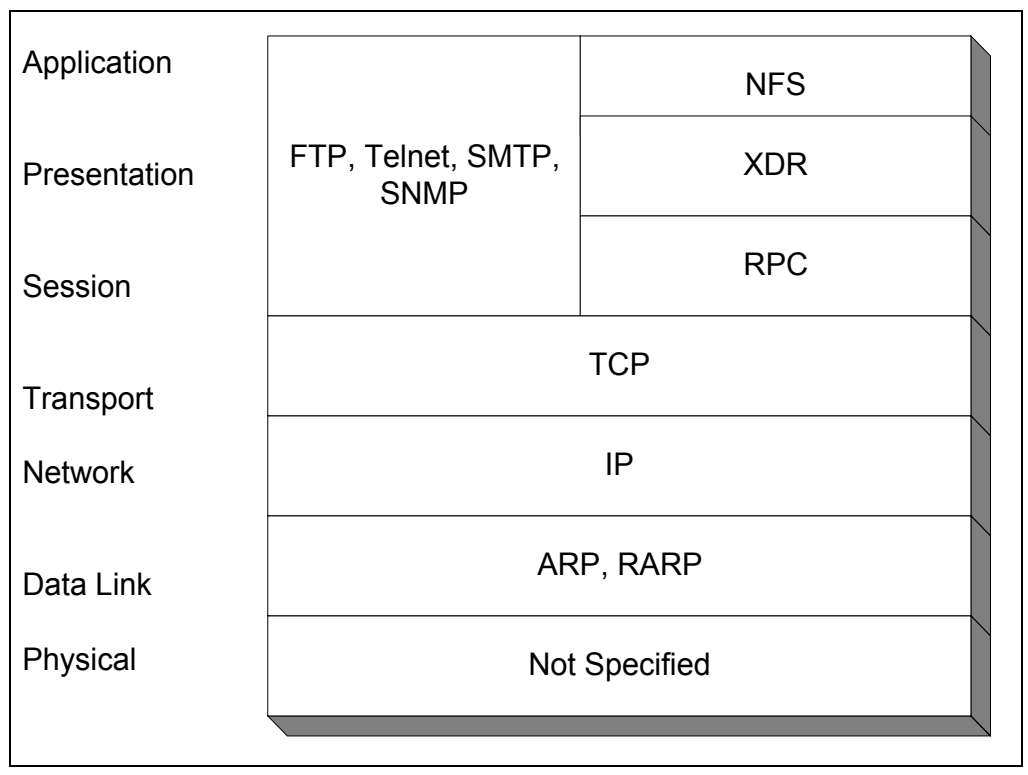

Figure 2. OSI model layers

The OSI model provides a conceptual framework for communication between computers, but the model itself is not a method of communication. Actual communication is made possible by using communication protocols. In the context of data networking, a protocol is a formal set of rules and conventions that governs how computers exchange information over a network medium. A protocol implements the functions of one or more of the OSI layers.

A wide variety of communication protocols exist, but all of them tend to fall into one of the following groups: LAN protocols, WAN protocols, network protocols, and routing protocols. LAN protocols operate at the physical and data link layers of the OSI model and define communication over the various LAN media. WAN protocols operate at the lowest three layers of the OSI model and define communication over the various wide-area media. Routing protocols are network-layer protocols that are responsible for path determination and traffic switching. Finally, network protocols are the various upper-layer protocols that exist in a given protocol suite. Table 2 summarizes the main tasks performed by each of the seven layers of the Open System Interconnection (OSI) reference model: Two key types of application-layer implementations are TCP/IP applications and OSI applications. TCP/IP applications are protocols, such as Telnet, FTP, and that exist in the Internet Protocol suite. OSI applications are protocols, such as FTAM, VTP, and CMIP that exist in the OSI suite. 


\section{CONVERGED NETWORKING}

Table 2. Seven layers of the open system interconnection (OSI) reference model

\begin{tabular}{|c|c|}
\hline No & Main Functions \\
\hline 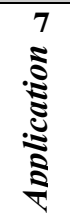 & $\begin{array}{l}\text { Functions typically include identifying communication partners, determining resource } \\
\text { availability, and synchronizing communication. Two key types of application-layer } \\
\text { implementations are TCP/IP applications and OSI applications. TCP/IP applications are } \\
\text { protocols, such as Telnet, FTP, and SMTP that exist in the Internet Protocol suite. OSI } \\
\text { applications are protocols, such as FTAM, VTP, and CMIP that exist in the OSI suite. }\end{array}$ \\
\hline 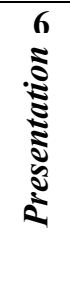 & $\begin{array}{l}\text { Provides a variety of coding and conversion functions that are applied to application layer data. } \\
\text { These functions ensure that information sent from the application layer of one system will be } \\
\text { readable by the application layer of another system. Common data representation formats are } \\
\text { EBCDIC and ASCII. Some well-known standards for video include QuickTime MPEG. Among } \\
\text { the well-known graphic image formats are GIF, JPEG, and TIFF. GIF is a standard for } \\
\text { compressing and coding graphic images. JPEG is another compression and coding standard for } \\
\text { graphic images, and TIFF is a standard coding format for graphic images. }\end{array}$ \\
\hline $\begin{array}{l}5 \\
5 \\
\vdots \\
5 \\
5 \\
5\end{array}$ & $\begin{array}{l}\text { Establishes, manages, and terminates communication sessions between presentation layer } \\
\text { entities. Communication sessions consist of service requests and service responses that occur } \\
\text { between applications located in different network devices. Some examples of session-layer } \\
\text { implementations include ZIP, the AppleTalk protocol that coordinates the name binding process; } \\
\text { and SCP, the DECnet Phase IV session-layer protocol. }\end{array}$ \\
\hline 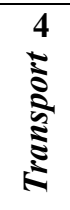 & $\begin{array}{l}\text { Implements reliable inter-network data transport services that are transparent to upper layers. } \\
\text { Functions typically include flow control, multiplexing, virtual circuit management, and error } \\
\text { checking and recovery. Some transport-layer implementations include TCP, NBP, and OSI } \\
\text { transport protocols. }\end{array}$ \\
\hline 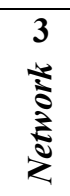 & $\begin{array}{l}\text { Provides routing and related functions that enable multiple data links to be combined into an } \\
\text { inter-network. Some common routing protocols include BGP, an Internet inter-domain routing } \\
\text { protocol; OSPF, a link-state, interior gateway protocol developed for use in TCP/IP networks; } \\
\text { and RIP, an Internet routing protocol that uses hop count as its metric. }\end{array}$ \\
\hline 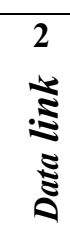 & $\begin{array}{l}\text { Provides reliable transit of data across a physical network link. Different data link layer } \\
\text { specifications define different network and protocol characteristics, including physical } \\
\text { addressing, network topology, error notification, sequencing of frames, and flow control. }\end{array}$ \\
\hline 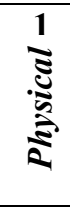 & $\begin{array}{l}\text { Responsible for actually placing information on the medium. It defines the electrical, mechanical, } \\
\text { procedural, and functional specifications for activating, maintaining, and deactivating the } \\
\text { physical link between communicating network systems. Its specifications define voltage levels, } \\
\text { timing of voltage changes, physical data rates, maximum transmission distances, and physical } \\
\text { connectors. }\end{array}$ \\
\hline
\end{tabular}




\subsection{Transmission Control Protocol/Internet Protocol (TCP/IP)}

TCP/IP is a set of communications protocols, that grew out of a research project that was funded by the U.S. Department of Defense. The TCP/IP networking scheme implements peer-to-peer client-server architecture. Any computing system in the network can run TCP/IP server software and can provide services to any other computing system that runs complementary TCP/IP client software. In TCP/IP, a connection Internet layer protocol that provides the best-efforts datagram delivery service.

Note that the functional layer TCP/IP corresponds to the OSI model network layer. The Internet layer provides routing and relaying functions that are used when data must be passed from a host to some other network in the Internet. It operates in the source and destination hosts and in all the routers along the path between the hosts (Comer 1999).

Table 3. Comparisons of communication switching techniques

\begin{tabular}{|c|c|c|c|}
\hline Circuit Switching & Message Switching & $\begin{array}{l}\text { Datagram Packet } \\
\text { Switching }\end{array}$ & $\begin{array}{c}\text { Virtual Circuit } \\
\text { Packet Switching }\end{array}$ \\
\hline $\begin{array}{l}\text { Dedicated transmission } \\
\text { path }\end{array}$ & No dedicated path & No dedicated path & No dedicated path \\
\hline $\begin{array}{l}\text { Continuous } \\
\text { transmission of data }\end{array}$ & $\begin{array}{l}\text { Transmission of } \\
\text { messages }\end{array}$ & $\begin{array}{l}\text { Transmissions of } \\
\text { packets }\end{array}$ & $\begin{array}{l}\text { Transmissions of } \\
\text { packets }\end{array}$ \\
\hline $\begin{array}{l}\text { Fast enough for } \\
\text { interactive }\end{array}$ & Too slow for interactive & $\begin{array}{l}\text { Fast enough for } \\
\text { interactive }\end{array}$ & $\begin{array}{l}\text { Fast enough for } \\
\text { interactive }\end{array}$ \\
\hline Messages are not stored & $\begin{array}{l}\text { Messages are filed for } \\
\text { later retrieval }\end{array}$ & $\begin{array}{l}\text { Packets may be stored } \\
\text { until delivered }\end{array}$ & $\begin{array}{l}\text { Packets are stored } \\
\text { until delivered }\end{array}$ \\
\hline $\begin{array}{l}\text { The paths is established } \\
\text { for entire conversation }\end{array}$ & $\begin{array}{l}\text { Route established per } \\
\text { message }\end{array}$ & $\begin{array}{l}\text { Route established per } \\
\text { packet }\end{array}$ & $\begin{array}{l}\text { Route may be } \\
\text { established for entire } \\
\text { conversation }\end{array}$ \\
\hline $\begin{array}{l}\text { Call setup plus } \\
\text { negligible transmission } \\
\text { delay }\end{array}$ & $\begin{array}{l}\text { Message transmission } \\
\text { delay per hop }\end{array}$ & $\begin{array}{l}\text { Packet transmission } \\
\text { delay per hop }\end{array}$ & $\begin{array}{l}\text { Call setup plus packet } \\
\text { transmission delay }\end{array}$ \\
\hline $\begin{array}{l}\text { Busy signal if called } \\
\text { party is busy }\end{array}$ & No busy signal & $\begin{array}{l}\text { Sender may be notified } \\
\text { if packet not delivered }\end{array}$ & $\begin{array}{l}\text { Sender notified of } \\
\text { connection denial }\end{array}$ \\
\hline $\begin{array}{l}\text { Overload may block } \\
\text { call setup: no delay for } \\
\text { established call }\end{array}$ & $\begin{array}{l}\text { Overload increases } \\
\text { message delay }\end{array}$ & $\begin{array}{l}\text { Overload increases } \\
\text { packet delay }\end{array}$ & $\begin{array}{l}\text { Overload may block } \\
\text { call setup: increases } \\
\text { packet delay }\end{array}$ \\
\hline $\begin{array}{l}\text { User responsible for } \\
\text { message loss protection }\end{array}$ & $\begin{array}{l}\text { Network responsible for } \\
\text { messages }\end{array}$ & $\begin{array}{l}\text { Network may be } \\
\text { responsible for } \\
\text { individual packets }\end{array}$ & $\begin{array}{l}\text { Network may be } \\
\text { responsible for packet } \\
\text { delay }\end{array}$ \\
\hline $\begin{array}{l}\text { Usually no speed or } \\
\text { code conversion }\end{array}$ & $\begin{array}{l}\text { Speed and code } \\
\text { conversion }\end{array}$ & $\begin{array}{l}\text { Speed and code } \\
\text { conversion }\end{array}$ & $\begin{array}{l}\text { Speed and code } \\
\text { conversion }\end{array}$ \\
\hline $\begin{array}{l}\text { Fixed Bandwidth for } \\
\text { call duration }\end{array}$ & $\begin{array}{l}\text { Dynamic use of } \\
\text { bandwidth }\end{array}$ & $\begin{array}{l}\text { Dynamic use of } \\
\text { bandwidth }\end{array}$ & $\begin{array}{l}\text { Dynamic use of } \\
\text { bandwidth }\end{array}$ \\
\hline $\begin{array}{l}\text { No overhead bits after } \\
\text { call setup }\end{array}$ & $\begin{array}{l}\text { Overhead bits in each } \\
\text { message }\end{array}$ & $\begin{array}{l}\text { Overhead bits in each } \\
\text { packet }\end{array}$ & $\begin{array}{l}\text { Overhead bits in each } \\
\text { packet }\end{array}$ \\
\hline
\end{tabular}

\subsection{Information Formats}

Common information formats include frame, packet, datagram, segment, message, cell, and data unit. A frame is an information unit whose source and destination are data link layer entities. A frame is 


\section{CONVERGED NETWORKING}

composed of the data-link layer header (and possibly a trailer) and upper-layer data. A packet is an information unit whose source and destination are network-layer entities. A packet is composed of the network-layer header (and possibly a trailer) and upper-layer data. Data from upper-layer entities is encapsulated in the network-layer header and trailer.

The term datagram usually refers to an information unit whose source and destination are networklayer entities that use connectionless network service. A message is an information unit whose source and destination entities exist above the network layer (often the application layer). A cell is an information unit of a fixed size whose source and destination are data-link layer entities. Cells are used in switched environments, such as ATM and SMDS networks. A cell is composed of the header and payload. The header is typically 5 bytes long. The payload contains upper-layer data that is encapsulated in the cell header and is typically 48 bytes long (Comer 1999).

\subsection{Connection-Oriented and Connectionless Network Services}

In general, networking protocols and the data traffic that they support can be characterized as being either connection-oriented or connectionless. In brief, connection-oriented data handling involves using a specific path that is established for the duration of a connection. Connectionless data handling involves passing data through a permanently established connection.

Connection-oriented network service carries two significant disadvantages over connectionless, static-path selection and the static reservation of network resources. Connection-oriented services, however, are useful for transmitting data from applications that don't tolerate delays and packet resequencing. Voice and video applications are typically based on connection-oriented services. As another disadvantage, connectionless network service does not predetermine the path from the source to the destination system, nor are packet sequencing, data throughput, and other network resources guaranteed.

Connectionless service, however, offers two important advantages over connection-oriented service: dynamic-path selection and dynamic-bandwidth allocation. Connectionless services are useful for transmitting data from applications that can tolerate some delay and resequencing. Databased applications typically are based on connectionless service. Table 3 presents a comparison of communication switching techniques.

\section{Networking Technologies}

The networking technologies are the means by which the multimedia is transported. Thus, in this section, the major characteristics of such technologies will be described.

\subsection{Asynchronous Transfer Mode (ATM)}

Asynchronous Transfer Mode (ATM) is a networking technology that contains a flexible multiplexing and switching technique, which provides variable bandwidth for local-area and wide-area networks. Unlike ordinary synchronous configurations, ATM permits flexible allocation of available bandwidth for data, voice, images and video (Onvural 1995). ATM uses a scalable architecture, making it easily upgradable; it allows a virtually unlimited number of users to have dedicated, high-speed connections with high-performance network servers (Zhou et.al. 1995).

A connection-oriented technology, ATM delivers true QoS on a per-connection basis, allowing for the convergence of voice, video, and data traffic. Because it guarantees the necessary bandwidth and latency characteristics while protecting each call from the effects of every other call on the backbone, QoS is vital for real-time applications such as videoconferencing or video-on-demand. Bursty data traffic on one connection, for example, will not impact the smooth flow of real-time voice and video on another. Interconnection of these types of networks is shown in figure 3 above.

ATM uses a connection-oriented operation. It establishes a sequence of switches, so that a connection is made from the source to the destination. Such a connection is called a virtual circuit connection (VCC) 
Prycher (1995). The switches can be established to perform simplex, duplex, multicast, and broadcast communications. A virtual connection (VC) is a connection between a switching node and the next node; hence, a VCC consists of a series of VC's. There are two kinds of VCs: 1) a permanent VC (PVC) for a leased line and 2) a switched VC (SVC) for a dynamically established connection. To simplify the management of VC's, a number of VC's with the same starting and ending node is grouped together as a virtual path (VP). To identify a VP or a VC, a number is used as the identifier and is labeled VPI/VCI (VP identifier/VC identifier) (Liew 2000).

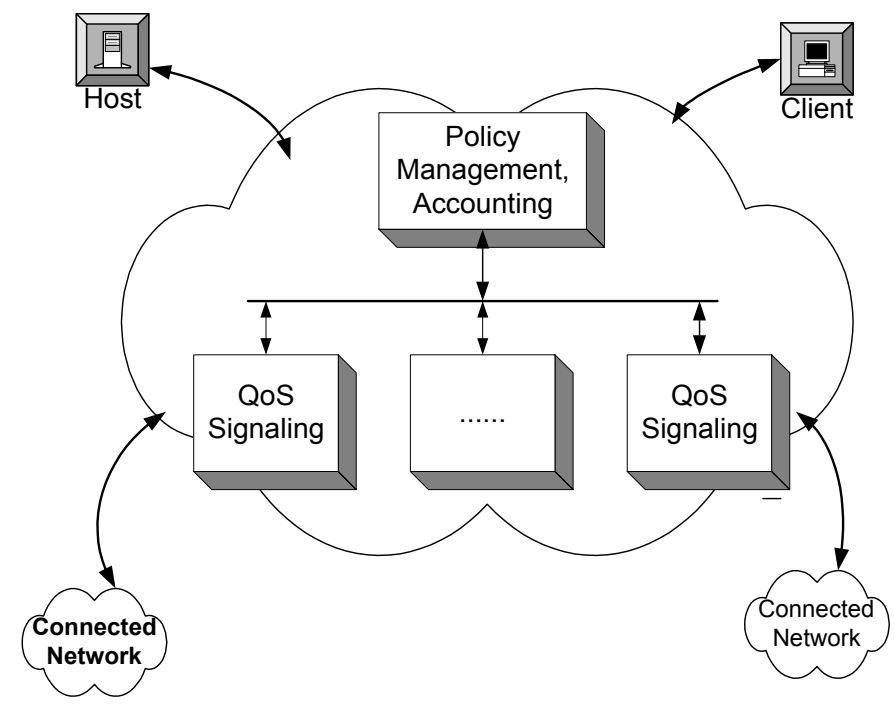

Figure 3. Basic QoS implementation

\subsection{Ethernet}

A form of LAN data link that uses IEEE 802.3/ISO 8802-3 carrier-sense multiple access with collision detection $(\mathrm{CSMA} / \mathrm{CD})$ standards. The Ethernet was originally designed to connect stations by a coaxial cable (10BASE5, thick cable and 10BASE2, thin cable), and later, it evolved to use twisted pairs to connect stations to a hub (10BASE-T). The transport rate is $10 \mathrm{Mb} / \mathrm{s}$. To improve the rate, the fast Ethernet (100BASE-T) was developed to accommodate $100 \mathrm{Mb} / \mathrm{s}$ and must use a hub to connect stations. The 100BASE-T can use two pairs of category 5 UTP (unshielded twisted pair) or four pairs of category 3 UTP cables. Ethernet has survived as an essential media technology because of its tremendous flexibility and its relative simplicity to implement and understand. Fast Ethernet is $100 \mathrm{Mbps}$ version of the CSMA/CD (Ethernet) standard. Gigabit Ethernet is Ethernet that provides speeds of 1000 Mbps (1000 base-X). It uses the same Ethernet frame format and media access control technology as all other 802.3 Ethernet technologies. It also uses the same 802.3 full-duplex Ethernet technologies and 802.3 flow control. Like its Ethernet and Fast Ethernet precursors, Gigabit Ethernet is a physical (PHY) and MAC layer technology, specifying the Layer 2 data link layer of the OSI protocol model.

\subsection{Frame Relay}

Frame Relay is a high-performance WAN protocol that operates at the physical and data link layers of the OSI reference model. Frame Relay originally was designed for use across Integrated Services Digital Network (ISDN) interfaces. Today, it is used over a variety of other network interfaces as well. Frame Relay is an example of a packet-switched technology. Packet-switched networks enable end stations to 


\section{CONVERGED NETWORKING}

dynamically share the network medium and the available bandwidth. Variable-length packets are used for more efficient and flexible transfers. These packets then are switched between the various network segments until the destination is reached. Statistical multiplexing techniques control network access in a packet-switched network. The advantage of this technique is that it accommodates more flexibility and more efficient use of bandwidth. Most of today's popular LANs, such as Ethernet and Token Ring, are packet-switched networks.

\subsection{Synchronous Optical Network (SONET) and Broad-band Integrated Service Digital Network (BISDN)}

The SONET was developed by Bellcore for wide area networking and it is an American National Standard Institute (ANSI) standard that is used in the U.S. and Canada. The European counterpart, synchronous digital hierarchy (SDH) is an ITU-T standard. The SONET and SDH are physically compatible at synchronous transport signal STS-3C $(155.52 \mathrm{Mb} / \mathrm{s})$ and synchronous transport module STM-1. The SONET uses a frame to carry lower-speed information (tributaries: video, audio, and data). The bandwidth for each tributary is guaranteed. The SONET uses synchronous multiplexing (SMUX) and add/drop multiplexers (ADM) to insert a signal from a source and to extract a signal at the destination.

The BISDN uses ATM over the SONET to multiplex signals. The cells are packed in the SONET frame's payload. BISDN provides LAN and metropolitan area network (MAN) connections, including 802.X, FDDI, frame relay, and switched multimegabit data service (SMDS).

\subsection{Fiber Distributed Data Interface (FDDI)}

Fiber Distributed Data Interface is a networking technology that uses a dual ring topology, often with dual networking equipment (concentrators, etc.). FDDI facilitates redundancy and protection of the network. If a device fails, the primary and secondary rings enter a "wrap" state to form a logical connection and thus maintain the logical ring in the event of a link failure. FDDI is capable of data rates of $100 \mathrm{Mbps}$ over fiber optic cable (SMF and MMF)

\subsection{Digital Subscriber Line}

Digital Subscriber Line (DSL) technology is a modem technology that uses existing twisted-pair telephone lines to transport high-bandwidth data, such as multimedia and video, to service subscribers. The term xDSL covers a number of similar yet competing forms of DSL technologies, including ADSL, SDSL, HDSL, RADSL, and VDSL. xDSL is drawing significant attention from implementers and service providers because it promises to deliver high-bandwidth data rates to dispersed locations with relatively small changes to the existing telecommunication infrastructure.

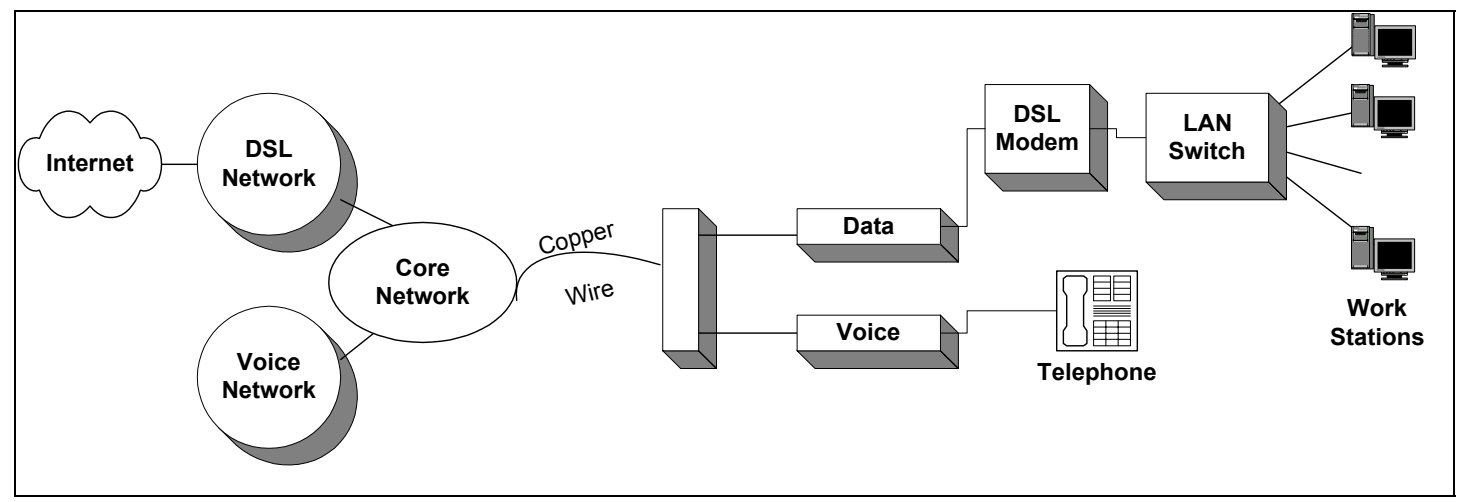

Figure 4. A typical DSL utilization 
This technology offers capability to utilize twisted pair copper wires for high-speed data and voice communications. See figure 4 for its typical configuration. xDSL services are dedicated, point-to-point, public network access on the local loop between a network service provider's (NSP's) central office and the customer site, or on local loops created either intra-building or intra-campus. Currently the primary focus in $\mathrm{xDSL}$ is the development and deployment of ADSL technologies and architectures.

\subsection{Asymmetric Digital Subscriber Line (ADSL)}

ADSL technology is asymmetric. It allows more bandwidth downstream from an NSP's central office to the customer site than upstream from the subscriber to the central office. This asymmetry, combined with always-on access (which eliminates call setup), makes ADSL ideal for Internet/intranet surfing, videoon-demand, and remote LAN access. Users of these applications typically download much more information than they send.

ADSL down stream rate ranges from 1.544 Mbps for distances of less than $5.5 \mathrm{~km}$ to $8.448 \mathrm{Mbps}$ for distances of less than $2.7 \mathrm{~km}$. The upstream speeds ranges from $16 \mathrm{kbps}$ to $640 \mathrm{kbps}$ (see Table 7 depicting the Copper Access Transmission speeds). Such rates expand existing access capacity by a factor of 50 or more without new cabling. ADSL can literally transform the existing public information network from one limited to voice, text, and low-resolution graphics to a powerful, ubiquitous system capable of bringing multimedia, including full motion video, to every home at the beginning of the 21 st century.

\section{Multimedia}

\subsection{Multimedia Technologies and Standards}

Table 4 summarizes some of the popular and widely used multimedia technologies or products. QuickTime, Video for Windows, and Indeo (Intel Video, and the new International Standard Organization (ISO) standard entitled Multimedia and Hypermedia Information Coding Expert Group (MHEG) (Ganter 1997 and Kathleen 1996).

\section{2 Compression Standards}

Table 5 presents a summary of some of the most prominent compression standards (Hwa wu et.al. 1998). developed by the ISO, viz., JPEG for still pictures and MPEG for motion pictures. The proprietary Graphics Interchange Format (GIF) is the most widely used format in the Internet and Bulletin Board Service.

\section{Converged Networking}

Several convergence strategies have been recently presented in the literature. Two convergence scenarios are briefly outlined in this section. A comprehensive discussion is planned for Part 2 of this paper.

\subsection{Convergence Between Public Switching and the Internet}

The Internet has evolved from a classical, closed-community data network into the infrastructure for the global information society. However, performance degradation in the trunk networks due to long holding times of subscribers logged into the Internet, has resulted in serious degradation of PSTN/ISDN user services and substantial loss of PSTN/ISDN operator revenue due to (Ulrich et.al., 1998):

- Lost calls to subscribers who are busy due to Internet usage.

a Migration of PSTN/ISDN services into the Internet, for example fax replaced by e-mail and voice telephony potentially replaced by low-quality voice over IP. 


\section{CONVERGED NETWORKING}

To counteract such effects, either external xDSL devices can be used to divert the Internet traffic into a data network before it hits the PSTN/ISDN, or controlling Internet traffic in the Central Office as part of PSTN/ISDN traffic in an optimized manner (Jeon et.al. 1998 and Barzilai et.al. 1998).

Table 4. Multimedia technologies and standards

\begin{tabular}{|c|c|c|c|}
\hline $\begin{array}{l}\text { Multimedia } \\
\text { Technologies }\end{array}$ & Developer & $\begin{array}{l}\text { Compression \& } \\
\text { Playback }\end{array}$ & Application \\
\hline $\begin{array}{l}\text { QuickTime } \\
\text { Used for PC and } \\
\text { Macintosh }\end{array}$ & $\begin{array}{c}\text { Apple } \\
\text { Computer }\end{array}$ & Software & $\begin{array}{l}\text { Supports Motion Picture Expert Group } \\
\text { (MPEG), an ISO compression standard, } \\
\text { Indeo (Intel Video), Kodak's photo CD } \\
\text { format, and Musical Instrument Digital } \\
\text { Interface (MIDI) }\end{array}$ \\
\hline $\begin{array}{l}\text { Video for } \\
\text { Windows } \\
\text { Designed } \\
\text { specifically for PC }\end{array}$ & Microsoft & Software & $\begin{array}{l}\text { Designed to playback videos in a small } \\
\text { window using software; the size of small } \\
\text { windows is } 320 \times 240 \text { pixels (quarter } \\
\text { VGA screen) in an Intel } 486 \text { computer or } \\
640 \times 480 \text { pixels (VGA screen) in an Intel } \\
\text { Pentium computer equipped with a } \\
\text { graphics accelerator }\end{array}$ \\
\hline $\begin{array}{l}\text { Indeo (Intel } \\
\text { Video) }\end{array}$ & $\begin{array}{l}\text { David Sarnoff } \\
\text { Research } \\
\text { Center }\end{array}$ & $\begin{array}{c}\text { Hardware } \\
\text { Card: digital } \\
\text { video interface } \\
\text { (DVI) }\end{array}$ & $\begin{array}{l}\text { Can achieve 160: } 1 \text { compression ratios } \\
\text { and store } 70 \text { min of video on a CD-ROM. } \\
\text { A major application of Indeo is } \\
\text { videoconferencing. }\end{array}$ \\
\hline MPEG & ISO & & $\begin{array}{l}\text { Distribution of interactive multimedia } \\
\text { applications in a multi vendor client } \\
\text { /server environment }\end{array}$ \\
\hline
\end{tabular}

\subsection{Convergence Between ATM and Ethernet}

The most widely used LAN, the Ethernet, has low throughput and scalability problems and is not suitable for multimedia communication. It is important to overcome these problems without a significant amount of new investment. There are several new developments on the horizon (Delgrosi et.al. 1995 and Garrahen et.al. 1993).

- Priority access control enabled workgroup switch (PACE) gives multimedia communication a high priority and improves the Ethernet efficiency to $98 \%$.

a Cell in frames (CIF) allows conversion between the ATM cells and the Ethernet frame format, so the ATM cells can reach an Ethernet station without the need to replace the NIC in a computer (Zhou et.al. 1999). 
ADEL.AHMED.ALI and AHMED M.AL-NAAMANY

Table 5. Compression standards

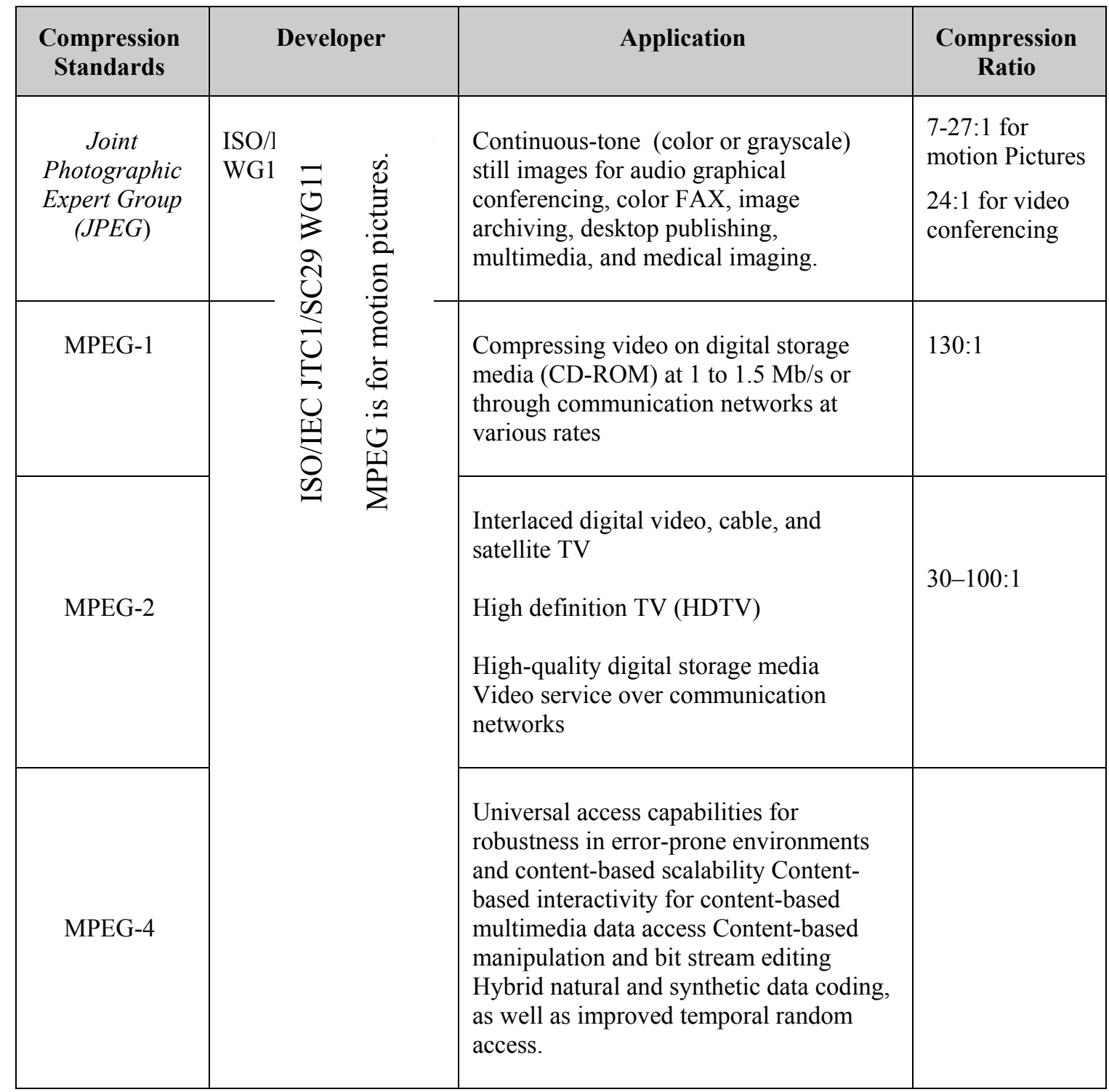

Table 6 compares typical bit rate requirements of some video services, with and without the use of compression. 


\section{CONVERGED NETWORKING}

Table 6. Bit rate requirements of video services

\begin{tabular}{|c|c|c|c|}
\hline Service & Example & Raw & Compressed \\
\hline \multirow{7}{*}{$\frac{8}{8}$} & $\begin{array}{l}\text { Real time (1/4 screen, low resolution) } \\
(126 \text { x } 120 \text { pixels) }(9 \mathrm{bits} / \text { pixel; } 15 \text { frames/sec.) }\end{array}$ & 2,074 & 64 \\
\hline & $\begin{array}{l}\text { Real time (1/4 screen, high resolution) } \\
(128 \times 240 \text { pixels })(9 \text { bits } / \text { pixel; } 15 \text { frames/sec.) }\end{array}$ & 4,147 & 384 \\
\hline & $\begin{array}{l}\text { Real time (full screen, high resolution) } \\
(128 \times 240 \text { pixels; } 9 \text { bits/pixel; } 30 \text { frames/sec.) }\end{array}$ & 8,294 & 2,000 \\
\hline & $\begin{array}{l}\text { Non-real time, low resolution server } \\
(352 \text { x } 240 \text { pixels; } 9 \text { bits/pixel; } 10 \text { frames/sec.) }\end{array}$ & 7,603 & 384 \\
\hline & $\begin{array}{l}\text { VCR-quality server } \\
\text { (352 x } 240 \text { pixels; } 24 \text { bits/pixel; 30-frames/ sec.) }\end{array}$ & 60,825 & 1,100 \\
\hline & $\begin{array}{l}\text { Studio quality server } \\
\text { ( } 640 \text { x } 480 \text { pixels; } 24 \text { bits/pixel; } 30 \text { frames/sec.) }\end{array}$ & 221,184 & 4,000 \\
\hline & $\begin{array}{l}\text { High-definition TV (HDTV) } \\
\text { (1,125 lines; } 24 \text { bits/pixel; } 30 \text { frames/sec.) }\end{array}$ & 800,000 & $\begin{array}{l}60,000- \\
127,000\end{array}$ \\
\hline
\end{tabular}

Table 7. Copper access transmission technologies

\begin{tabular}{|c|c|c|c|c|}
\hline Name & Meaning & Date Rate & Mode & Applications \\
\hline $\begin{array}{l}\text { V.22 } \\
\text { V.32 } \\
\text { V.34 }\end{array}$ & Voice Band Modems & $\begin{array}{l}1200 \mathrm{bps} \text { to } \\
28,800 \mathrm{bps}\end{array}$ & Duplex & Data communications \\
\hline DSL & Digital Subscriber Line & $160 \mathrm{kbps}$ & Duplex & $\begin{array}{l}\text { ISDN service } \\
\text { Voice and data communications }\end{array}$ \\
\hline HDSL & $\begin{array}{l}\text { High data rate Digital } \\
\text { Subscriber }\end{array}$ & $\begin{array}{l}1.544 \mathrm{Mbps}^{5} \\
2.048 \mathrm{Mbps}^{5}\end{array}$ & $\begin{array}{l}\text { Duplex } \\
\text { Duplex }\end{array}$ & $\begin{array}{l}\text { T1/E1 service } \\
\text { Feeder plant, WAN, LAN } \\
\text { access, server access }\end{array}$ \\
\hline SDSL & $\begin{array}{l}\text { Single line Digital } \\
\text { Subscriber line }\end{array}$ & $\begin{array}{l}1.544 \mathrm{Mbps} \\
2.048 \mathrm{Mbps}\end{array}$ & $\begin{array}{l}\text { Duplex } \\
\text { Duplex }\end{array}$ & $\begin{array}{l}\text { Same as HDSL plus premises } \\
\text { access for symmetric services }\end{array}$ \\
\hline ADSL & $\begin{array}{l}\text { Asymmetric Digital } \\
\text { Subscriber Line }\end{array}$ & $\begin{array}{l}1.5 \text { to } 9 \mathrm{Mbps} \\
16 \text { to } 640 \mathrm{kbps}\end{array}$ & $\begin{array}{l}\text { Down } \\
\text { Up }\end{array}$ & $\begin{array}{l}\text { Internet access, video on } \\
\text { Demand, simplex video, remote } \\
\text { LAN access, interactive } \\
\text { multimedia }\end{array}$ \\
\hline VDSL & $\begin{array}{l}\text { Very high data rate } \\
\text { Digital Subscriber Line }\end{array}$ & $\begin{array}{l}13 \text { to } 52 \mathrm{Mbps} \\
1.5 \text { to } 2.3 \mathrm{Mbps}\end{array}$ & $\begin{array}{l}\text { Down } \\
\text { Up }\end{array}$ & Same as ADSL plus HDTV \\
\hline
\end{tabular}




\section{Concluding Remarks}

We can conclude from the above review that, Ethernet (802.3) is the most widely used LAN standard and its upgrade fast Ethernet can provide connections of a $100 \mathrm{Mb} / \mathrm{s}$ rate. Previously widely used Token ring (802.5) provides both 4 and $16 \mathrm{Mb} / \mathrm{s}$ rates. 100VG-AnyLAN (802.12) provides $100 \mathrm{Mb} / \mathrm{s}$ for multimedia communication. Switched LAN's provide better efficiency, whereas the shared media LAN's can experience problems in scaling up.

Developments in Fiber optics technologies are expected to further improve LAN and WAN transmissions to $10 \mathrm{~Gb} / \mathrm{s}$ over a single fiber. High Capacity electronic IP routers are in development and are expected to reach several Terabits per second. These advancements and attempts to extend these highdata-rate capabilities to the high end users will revolutionize the networks capabilities (Kuznetsou. 2000).

Gigabit Ethernet has the capability to provide gigabit connections among hubs and servers, so there is more bandwidth for multimedia communication. H.320 is a videoconferencing standard over ISDN, H.323 is used for shared computer networks (such as LAN's and the Internet), and H.324 is used for POTS(Plain Old Telephony System).

ATM will be the standard for delivering MPEG-2 high-quality video over network (Worsley et.al. 1997). DSL/CATV will deliver broadband information to users directly. Multimedia applications with high-quality video will significantly enhance the information exchange, which, in turn, will stimulate many industrial applications that have in the past been considered impossible. ATM provides QoS that is critical for multimedia communication. SONET is the standard for a high-speed WAN. The seamless integration of frame switching with cell switching would have a potential of merging frame relay with ATM (Liew 2000 and Awdeh et.al. 1995).

It is evident that XDSL will play a crucial role over the next decade or more as telephone companies enter new markets for delivering information in video and multimedia formats. New broadband cabling will take decades to reach all prospective subscribers. Success of these new services will depend on reaching as many subscribers as possible during the first few years. By bringing movies, television, video catalogs, remote CD-ROMs, corporate LANs, and the Internet into homes and small businesses, xDSL will make these markets viable and profitable for telephone companies and application suppliers alike.

The Central Office (CO) of today will evolve into an optimized Internet access point that fully supports the telecom operators' strategy to reuse their investment in the PSTN/ISDN infrastructure and to provide new subscriber services based on Internet technology. Such approach enables evolutionary extensions for broadband subscriber access starting from the installed narrow band infrastructure in the PSTN/ISDN balancing user demand for Internet services with telecommunication investments. This approach contributes to a convergence of PSTN/ISDN and the Internet toward a seamless multimedia network of the future.

Convergence of the telecommunications and computer industries to a common vision of networking models for an integrated services information infrastructure is essential to meet the stringent requirements of multimedia applications. On the other hand, ATM and Gigabit Ethernet may each dominate certain markets, and they may compete in others. However, researchers are already trying to incorporate the capabilities of each technology into the other. They have developed RSVP to give Ethernet networks capabilities along the lines of ATM's quality of service, as well as LAN emulations to let an ATM network connect to Ethernet desktops. In addition, vendors are working on bridges, routers, and switches that will connect the two technologies.

The growing use of multimedia communication applications with specific bandwidth and real time delivery requirements has created the need for an integrated services Internet in which traditional best effort datagram delivery can coexist with additional enhanced quality of service (QoS) delivery classes. Such classes provide data flow with QoS commitments with regard bandwidth, packet loss, and delay through the reservation network resources along the data path, which can be done using the Resources Reservation Protocol (RSVP). 


\section{CONVERGED NETWORKING}

\section{References}

AWDEH, R. and MOUFTAH, H. 1995. Survey of ATM switch architectures, Computer Networks and ISDN Syst. vol. 27: $1567-1613$.

BARZILAI, T. P, KANDLUR, D., MEHRA, A, and SAHA, D. 1998. Design and Implementation of an RSVP-Based Quality of Service Architecture for an Integrated Services Internet. IEEE journal on Selected Areas in Communications, 16: 397-413.

BRADEN. R, CLARK. D, and SHENKER. S. 1997. Integrated services in the Internet architecture: An overview, request for comments. Internet Engineering Task Force, IETF RFC 1633. [Online]. (July 1994). Available FTP: ds.internic.net/rfc/rfc1633.txt.

CHANG, RUAY-SHIUNG, and WANG, CHIN-DONG, 1999. Improved WWW Multimedia Transmission Performance in HTTP/TCP over ATM Networks, IEEE Transactions on Multimedia 1: 278-290.

CHWAN-HWA WU, and IRWIN J. DAVID, 1998. Multimedia and multimedia Communication: a tutorial, IEEE Transactions on Industrial Electronics, 45(1): 4-14.

CISCO PLOTS Voice/Data Integration, Computer world. October 27, 1997; http://www.computerworld.com/.

COLLINS, J. C, DUNN, J. EMER, P and HOHNSON, M. Feb. 1999. Data Express. IEEE Sepectrum, 36: 18-25.

COMER, D. 1999. Computer Networks and Internet $2^{\text {nd }}$ ed. New Jersey, Prentice Hall.

DELGROSSI, L, and BERGER, L. 1995. Internet stream protocol Version 2 (ST2) protocol specification-Version ST2 , Internet Engineering Task Force, IETF RFC.1819. (Aug. 1995). [Online]. (Available FTP: ds.internic.net/rfc/rfc1190.txt.)

DE PRYCHER, M. 1995. Asynchronous Transfer Mode: Solution for Broadband ISDN, 3rd ed. Chichester, U.K.: Ellis Horwood.

GARRAHAN, J. J, RUSSO, P. A, KITAMI, K. and KUNG, R. 1993. Intelligent network overview, IEEE Commun. Mag., 31: 30-36.

GARTNER GROUP, 1997. Interactive Media: Integrative View and Commentary, March 28, 1997.

JEON, W.S, JEONG DONG GEUN, and CHOI CHONG-HO. 1998. An Integrated Services MAC Protocol for Local Wireless Communications, 1998. IEEE Transactions on Vehicular Technology, 47: 352-364.

LIEW, S.Y., Lee, T.T. 2000. Bandwidth assignment with QoS guarantee in a class of scalable ATM switches, IEEE Transactions on Communications, 48(3): 377 -380.

MARK KUZNETSOV, M.; FROBERG, N. M.; HENION, S.R.; RAO, H.G.; KORN, J.; RAUSCHENBACH, K.A.; MODIANO, E.H.; CHAN, V.W.S. A Next-Generation Optical Regional Access Network. IEEE Communication Magazine, 38(1): 66-72.

MURPHY, K. 1996. Multimedia Applications on Rise Within Corporate Webs: Shockwave, Other Tools Being More Widely Deployed, Webweek, December 6, 1996.

ONVURAL, R. 1995. Asynchronous Transfer Mode Networks: Performance Issues, 2nd ed. Norwood, MA: Artech House.

PEIFANG, Z. and OLIVER, Y. 1999. Integrated Cell and Frame Switching in ATM Networks, IEEE communications Letters, 3(6): 183-184.

RAFTER, M. V. 1997. Exodus Invests in Data Centers as High-End Outsourcing Market Booms. Webweek, December $15,1997$.

SCHOEN, U., HAMANN, J., JUGEL, A., KURZA, H., and SCHMIDT, C., 1998. Convergence Between Public Switching and the Internet, IEEE Communications Magazine, January 1998, pp 50-64

WHITE, P and CROWCROFT, J. 1997. The Integrated Services in the Internet: State of the Art, Proceedings of the IEEE, vol. 85, no. 12, December 1997, pp 1934-1946.

WORSLEY, D.J, and OGUNFUNMI, T.1997. Isochronous Ethernet-An ATM Bridge for Multimedia Networking, IEEE Multimedia, January-March 1997, pp 58-67.

ZHOU, P. and YANG, O. 1997. A new design of central-queueing ATM switches, in Proc. IEEE GLOBECOM'97: 541-545.

Received 31 January 2000

Accepted 30 June 2000 